\title{
Couple characteristics and outcome of therapy in vaginismus
}

In the article titled, "Couple characteristics and outcome of therapy in vaginismus' [1], Munasinghe and colleagues appear to have confused dyspareunia with vaginismus. Vaginismus is a classical psychosomatic disorder which usually results in complete apareunia and non-consummation of marriage. Milder forms of vaginismus can cause dyspareunia at coitarche and it may sometimes persist thereafter. Their reference to Rafla [2] with regard to avoidable causes of secondary vaginismus is incorrect. Rafla reported a case of bilateral vaginal tears occurring when an inexperienced person inserted a Cusco's bivalve vaginal speculum into a sexually active nulliparous woman with vaginismus.

Vulvo-vaginal trauma results in scarring, and usually leads to secondary dyspareunia, but it may rarely lead to subsequent vaginismus due to fear of recurrence of the injury. Infection on the other hand causes dyspareunia, and when it is treated it should not lead to vaginismus. Vulvovaginal infection and trauma, as well as developmental abnormalities, pelvic inflammatory disease, pelvic endometriosis and atrophy of the vaginal epithelium cause dyspareunia. Antibiotics, surgery, vaginal dilatation, local analgesics and hormones are all accepted forms of therapy depending on the cause of dyspareunia. Before embarking on treatment in a woman having coital difficulties, it is essential to differentiate between vaginismus and other causes of dyspareunia by obtaining a detailed history and carrying out a complete gynaecological examination.

The therapy of vaginismus described by Munashinghe and colleagues is the method of gradual vaginal desensitisation, which is extremely laborious, time consuming and not quite satisfactory $(80 \%$ success reported by them). The alternative is - the rapid vaginal desensitisation method [3]. This method involves insertion of a mould or large dilator into the vagina. No surgery is involved and the principle is simple desensitisation and not physical dilatation of the vagina. This method is easy, quick and rarely fails. However, it needs hospitalisation and a short general anesthetic. For this method to succeed, privacy and the presence of partner is essential for a minimum of 24 hours after the procedure. Therefore it is difficult to be carried out in a busy ward of a government hospital. The author has used this method with success in more than 60 patients during the last 17 years. 


\section{Correspondence}

\section{References}

1. Munasinghe T, Goonaratna C, De Silva P. Couple characteristics and outcome of therapy in vaginismus. Ceylon Medical Journal 2004; 49: 54-7.

2. Rafla N. Vaginismus and vaginal tears. American Journal of Obstetrics and Gynaecology 1988; 158: 1043-5.

3. Biswas A, Ratnam SS. Vaginismus and out come of treatment. Annals of Academy of Medicine, Singapore 1995; 24: 755-8.

I M R Goonewardene, Professor in Obstetrics and Gynaecology, Faculty of Medicine, P O Box 70, Galle, Sri Lanka. E-mail: <malikg@eureka.Ik>. 